\title{
Sorbent system based on acetylated microfibrillated cellulose for remediation of oil aquatic environments
}

Matheus Vinícius Gregory Zimmermann ${ }^{1}$, Ademir José Zattera ${ }^{2}$ Ruth Marlene Campomanes Santana ${ }^{3}$

\author{
${ }^{1}$ Universidade do Extremo Sul Catarinense (UNESC), Av. Universitária, 1105, CEP 88806-000, Criciúma, Santa Catari- \\ na, Brasil. \\ e-mail: matheus.vgz@gmail.com \\ ${ }^{2}$ Universidade de Caxias do Sul (UCS), R. Francisco Getúlio Vargas, 1130, CEP 95070-560, Caxias do Sul, Rio Grande \\ do Sul, Brasil. \\ e-mail: ajzatter@ucs.br \\ ${ }^{3}$ Universidade Federal do Rio Grande do Sul (UFRGS), Av. Bento Gonçalves, 9500, CEP 91501-970, Porto Alegre, Rio \\ Grande do Sul, Brasil. \\ e-mail: ruth.santana@ufrgs.br
}

\begin{abstract}
The growth of oil exploration and transport in marine environments brings concern over potential environmental disasters caused by oil spills. Thus, various materials are being developed and studied in order to minimize environmental impacts caused by these oil spills. Among these materials, the use of sorbents has appeared as a great potential technique for the treatment of effluents, by separating and collecting oil in the aqueous medium. This work describes the development of a sorbent system based on acetylated microfibrillated cellulose. Initially, cellulose fibers were modified by an acetylation reaction and thereafter, by a mechanical process using a wheel mill grinding. To produce the sorbent system, fibers were coated by three different types of envelopes to prevent leakage during the sorption experiment. Main results indicate a higher oil sorption by sorbents with higher oil viscosity and higher grammage of the envelope. Acetylated microfibrillated cellulose showed low water adsorption and high selectivity to oil and greater oil sorption values than commercially sorbent currently used, based on polypropylene fibers.
\end{abstract}

Keywords: sorbents, microfibrillated cellulose, acetylation.

\section{INTRODUCTION}

Oil contamination has been frequently reported with the expansion of oil exploration in marine environments and water transportation of petroleum products. Disasters involving oil spills bring disastrous consequences to the environment, human health, economy and management of non-renewable resources [1]. Traditionally, methods for disasters remediation caused by oil spills in marine environments include various techniques, such as burning, mechanical collecting, use of chemical dispersants, bioremediation and the sorbents technology [2].

In recent years, sorption has appeared as a high-potential technique for treatment of industrial effluents. In this context, various materials have been studied in the recovery of oil in marine environments and minimize environmental impacts caused by it [1,2]. It is important that these sorbents exhibit high oil sorption capacity and good selectivity between oil and water, high absorption rate, low density, preferably by addition of biodegradable, and low cost [3].

Duong and Burford (2006) [4] report that for a good efficiency of the sorbent, oil diffusion rate into the sorbent should be fast, in large quantities and without the system dissolution. The possibility of retaining the oil sorbent is an attractive possibility for the recovery of oil. However, in a system with a low degree of absorption and high absorption rate, the oil can seep out of the sorbent system before it completes its goal. Hydrophobic and oleophilic sorbents are materials which should float on the surface of water contaminated with oil, and selectively only remove oil from water, and after this, the entire system is removed by mechanical process [5]. Sorbents are materials that have a significant oil removal capacity and can sip 3-100 times its original mass, coupled with the fact that generally it has low cost and low harmful effects on the ecosystem 
[6].

In this context, many materials have been studied as sorbents in oil recovery in marine environments to minimize environmental impacts caused by it [1,2]. Currently, the main sorbent materials used in the recovery of marine oil spills are classified into three main categories: natural inorganic (glass wool, clays, perlite, others), organic natural (vegetable fibers, peat of sphagnum moss) and synthetic (polypropylene blankets and fibers and polyurethane foams) $[4,7,8]$. The drawback of using mineral inorganic sorbent is due to the fact that most of them have density higher than water, thus impeding its buoyancy, and also because of the fact that its vast majority is marketed in the form of powders, which limits the use to terrestrial environments or fluidized beds. Synthetic sorbents, such as polypropylene fibers, are produced from non-renewable sources, and in general have a high production cost and difficult recyclability. Based on this, sorbents from vegetal source have been attracted to be a promising class of materials for use as oil sorbents, mainly because of the abundance of raw materials provided by renewable sources, its biodegradability and its low cost. Some vegetables sorbents, as the kapok fiber, are originally hydrophobic due to a high concentration of wax in the fiber surface, making it a good candidate for use as sorbents. However, the small production scale, combined with climatic conditions cultivation of this tree also hamper their application on a large scale promoting in this case a high cost product.

In this sense, cellulose can be a material of great potential in use as absorbents. Cellulose is the main component in vegetable fibers and is responsible for strength, rigidity and dimensional stability to the cell wall of the plant species. Cellulose is a linear homopolysaccharide which consists of a repetition of Danhydroglucose $\left(\mathrm{C}_{6} \mathrm{H}_{11} \mathrm{O}_{5}\right)$ units linked by glycosidic bonds. Each repeating unit contains three hydroxyl groups, which impart hydrophilic character to the pulp and have a high ability to form hydrogen bonds, which governs not only their physical properties, but also the crystal packing [9-11].

Cellulose is a low density material, environment-friendly from a renewable and biodegradable source. It generally has low cost and a large-scale production. However, hydrophobicity is one of the properties that determines the efficiency of a nonpolar sorbent, especially when the objective is the removal of oil in aquatic environments [12]. To use cellulose as a sorbent material, it is first necessary to make it go through a chemical process in order to increase its hydrophobicity. Modifying chemical treatments of cellulose usually are made by replacing hydroxyl groups by nonpolar segments, which gives cellulose higher percentages of hydrophobicity necessary to interact with nonpolar oils.

Acetylation reaction is one of the most common techniques for hydrophobization of lignocellulosic material. The reaction occurs by replacing hydroxyl groups present in cellulose by acetyl groups. This reaction is generally performed using reagents such as acetic anhydride and acetic acid under specific conditions of heat, with or without the presence of a catalyst, as shown in Figure 1 [12].:

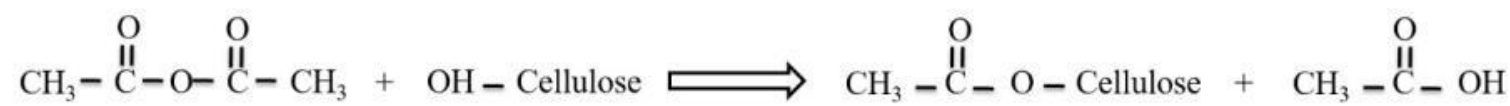

Figure 1: Representation of chemical modification of cellulose by acetylation.

Sun et al. (2004) [13] and Chung et al. (2011) [12], reported that, in the acetylation process, an efficient catalyst could shorten the reaction time in the acetylation of lignocellulose materials. The use of $\mathrm{N}$ bromosuccinimide (NBS) as catalyst has been demonstrated as a convenient and effective method. Nagarajappa et al. (2015) [14] reported the full mechanism of the acetylation reaction using NBS catalysts, and cites that, others catalyst has also been used in acetylation reactions, such as pyridine, but the toxic nature and unpleasant odor make pyridine unsuitable for large-scale applications [12-14].

Nanotechnology applied to cellulosic fibers has quickly become an interdisciplinary field with great interest in the application of reinforcement in polymer composites, mainly due to the abundance of these raw materials, their mechanical properties and multifunctionality [15]. The increased contact area from nanofibers, when compared to macrofibers, increases the sorbent efficiency, due to a larger area of interaction with the environment (oil) [16].

Recently the use of mechanical defibrillator, such as a grindstone mill, is being used in the obtaining of cellulose nanofibers or microfibrillated cellulose (MFC) as a more cost effective method if compared to chemical treatments to obtain nanocellulose, as acid-hydrolyzed and TEMPO-oxidized nanocellulose. When mechanically processing cellulose fibers, both amorphous and crystalline regions are kept, whereas with chemical treatments to obtain nanocellulose, most of the amorphous fraction is lost. This combined with the 
fact that the processing by defibrillation uses less aggressive solvents (in this case water) when compared to a large amount of chemicals generated by chemical treatments to obtain nanocelluose, such as acid hydrolysis or alkaline treatments [17].

The mechanical processing of ultra-fine milling consists in breaking the cell wall structure due to shear forces generated by the grinding stones which comprise the mill. To perform the defibrillation wheels in mills, pulp fiber is dispersed at low concentrations in water, and this suspension is forced to pass between two wheels, one rotating and the other static. The use of water as a base medium helps in the swelling of the cellulose fiber, and thereby facilitates the breaking of hydrogen bonds between the cellulose cell walls. The contact surfaces and the grooves of the wheels along with the repeated cyclic stresses result in the pulp defibrillation. The degree of fibrillation is associated with the distance between the wheels, the morphology of the channels (grooves in the grinding wheel) and the number of passages in the suspension system. The main advantage of this process is that there is no need for pre-treatment in order to obtain the nanofibers, depending on the final application of nanofibres [18].

One of the difficulties in the obtaining of MFC or cellulosic nanostructures is to maintain the nanoscale of the fiber during the drying process. In the conventional drying by water evaporation at high temperatures, an attraction between the cellulose fibers occurs, promoted by hydrogen bonds, due to the presence of hydroxyls groups on the cellulose surface, which promotes the formation of fiber agglomerations and loss of the nanoscale [19]. The agglomeration process in high temperatures drying (hornification) has often been reported as an irreversible or partially reversible bond between hydroxyl groups present in cellulose [20]. Thus, several techniques are used to remove the water from nanocellulose suspensions, but among the available ones, supercritical extraction is considered one of the most versatile and simple techniques for drying the system without compromising the initial system volume and the nanostructure of cellulose [19, 21].

In this context, this study aims at developing a sorbent system for oil removal from marine environments based on chemically modified micro-nanofibers of cellulose. Three different types of envelopes/packaging that recover the micro-nano cellulose fibers were tested, to evaluate the influence of the type of material, the weight, and the mesh opening of each envelope in the oil sorption. The cellulose system sorbent was also compared with a commercial sorbent based on polypropylene fibers.

\section{MATERIALS AND METHODS}

\subsection{Materials}

Bleached cellulose fibers (CF) obtained from eucalyptus trees were provided by Celulose Riograndense S.A. (Brazil/RS). The cellulose pulp was acquired in the form of sheets and pre-milled in a MARCONI knife mill with a $\varnothing 1 \mathrm{~mm}$ sieve prior to the chemical treatments for better separation of the cellulose fibers. The reagents used in the chemical modification of cellulose were: Acetic anhydride (cod V00023) supplied by Vetec Química Fina Ltda., acetic acid (cod A6283) and N-bromosuccinimide (NBS) (cod. B81255), both supplied by Sigma Aldrich SA. The tissues used in the development of the envelopes were: (a) $100 \%$ polypropylene, grammage $300 \mathrm{~g} . \mathrm{m}^{-2}$; (b) $100 \%$ polyester, grammage $55 \mathrm{~g} . \mathrm{m}^{-2}$; (c) $100 \%$ polypropylene, non-woven fabric, grammage 40 g.m $\mathrm{m}^{-2}$.

\subsection{Sorbents development}

Fifteen grams of cellulose fiber was placed in a $1000 \mathrm{~mL}$ round bottom flask containing a $400 \mathrm{~mL}$ solution of acetic anhydride and acetic acid (1.5:1 v/v) and 1\% n-bromosuccinimide (NBS) (4 g NBS dissolved in a 400 $\mathrm{mL}$ solution). The flask was then fit into a reflux condenser and heated to a temperature of $120^{\circ} \mathrm{C}$ over a $3 \mathrm{~h}$ period, at atmospheric pressure. After the reaction, $400 \mathrm{~mL}$ of distillated water was added to the treated cellulose, and then the suspension was filtered and washed with ethanol and acetone to remove any unreacted acetic anhydride and acetic acid byproducts. The resulting products were then dried in an oven at $60^{\circ} \mathrm{C}$ for $24 \mathrm{~h}$ and followed by $4 \mathrm{~h}$ at $120^{\circ} \mathrm{C}$.

Ultra-fine grinding of cellulose and acetylated cellulose was performed using a Masscolloider Masuko Sangyo, model MKCA6 - 2J wheel mill. Milling was performed in a solution containing water and 3\% cellulose/ acetylated cellulose. The equipment was coupled to a recirculating pump and the milling time was 4 hours at a speed of $1500 \mathrm{rpm}$.

Drying of MFC and acetylated MFC was performed with carbon dioxide - $\mathrm{CO}_{2}$, in a supercritical extractor. The equipment used was supplied by Supercritical Fluids, model FTS 150, with a 1L pressure vessel. For the drying process, at first a solvent exchange was conducted to replace the water/cellulose suspension 
for an alcohol/cellulose suspension. For this condition, MFC was vacuum filtered and washed with acetone and alcohol. After that, MFC was redispersed in an alcohol suspension with a 5\% cellulose concentration. After solvent exchange, the alcohol / cellulose suspension was stirred in a mechanical shear propeller mixer for 1 hour. The alcohol / cellulose suspension was added to the pressure vessel and $\mathrm{CO}_{2}$ was injected at a $2000 \mathrm{psi}$ pressure and a temperature of $45^{\circ} \mathrm{C}$ was maintained for 1 hour. Then, the dynamic extraction valve and the $\mathrm{CO}_{2}$ feed was opened to promote solvent extraction. Total extraction time was 6 hours. Cylinder depressurization occurred for 20 hours.

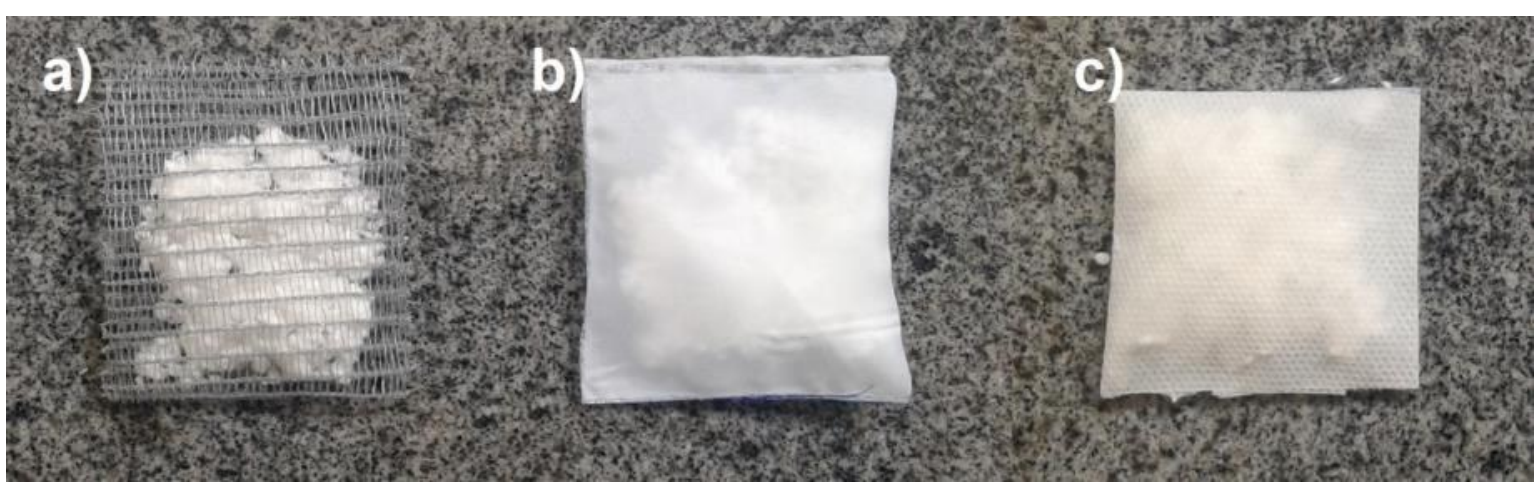

Figure 2: Specimens for sorption assay with envelopes of: a) polypropylene; b) polyester and c) polypropylene

The sorbents specimens were produced with $0.5 \pm 0.01 \mathrm{~g}$ of cellulose, coated by $50 \times 50 \mathrm{~mm}$ envelopes, as shown in Figure 2. It was used three kinds of synthetic tissues (type A - polypropylene, type B polyester and type $\mathrm{C}$ - polypropylene), with different grammage in the manufacture of sorbents.

\subsection{Characterizations}

The morphology of the samples was evaluated by scanning electron microscopy (SEM) using a Shimadzu equipment, SuperScan model SS-550. Before the observation, the samples were stuck onto a sample platform, and sputtered with gold in a sputter coater.

The chemical analysis was performed by Fourier Transform Infrared spectroscopy (FTIR) in a Thermo Scientific Nicolet, model iS10 instrument on Attenuated total reflectance (ATR) method. The samples were scanned in the region from 4000 to $400 \mathrm{~cm}^{-1}$ with resolution of $4 \mathrm{~cm}^{-1}$.

Thermogravimetric analysis (TGA) of the samples was performed using a Shimadzu, Model 50-TGA instrument at a heating rate of $10^{\circ} \mathrm{C} \cdot \mathrm{min}^{-1}$ and heating ramp from 23 to $800^{\circ} \mathrm{C}$ under a $\mathrm{N}_{2}$ atmosphere $(50$ $\left.\mathrm{mL} \cdot \mathrm{min}^{-1}\right)$.

The static adsorption test was conducted according to ASTM F726-12. The sorbent was exposed to oil and water (separately) for a period of $15 \mathrm{~min}$, removed and kept suspended for 30 seconds to drain the excess oil. The sample was weighed before and after the sorption test. In this experiment three different types of oils with different viscosity were used, as shown in Table 1 . The three oils are considered paraffinic minerals and were chosen as they differ mainly in the viscosity.

Table 1: Oils used in sorption test.

\begin{tabular}{cccc}
\hline Oil & $\begin{array}{c}\text { Density at 20-40 } \\
\left(\mathbf{g} / \mathbf{c m}^{\mathbf{3}}\right)\end{array}$ & $\begin{array}{c}\text { Kinematics Viscosity } \\
(\mathbf{c S t})\end{array}$ & $\begin{array}{c}\text { ASTM F726-12 } \\
\text { Classification }\end{array}$ \\
\hline SAE 140w & 0.93 & 400 & Heavy \\
SAE 20W50 & 0.88 & 64 & Medium \\
Kerosene & $0.82-0.85$ & 3.5 & Light \\
\hline
\end{tabular}

\section{RESULTS AND DISCUSSION}

Figure 3 shows the results of the FTIR analysis before and after the acetylation chemical treatment of the cellulose fibers. The characteristic bands of pure cellulose are: $3500 \mathrm{~cm}^{-1}$, corresponding to hydroxyl $(\mathrm{OH})$ groups; $2950 \mathrm{~cm}^{-1}$, corresponding to the $\mathrm{CH}_{2}$; and $1049 \mathrm{~cm}-1$, corresponding to $\mathrm{C}-\mathrm{O}$. In acetylated cellulose, the presence of band $1740 \mathrm{~cm}^{-1}$ is associated with carbonyl group $(\mathrm{C}=\mathrm{O}), 1365 \mathrm{~cm}^{-1}$ refers to the $\mathrm{C}-\mathrm{CH}_{3}$, and 
the bands 1225 and $1033 \mathrm{~cm}^{-1}$ are associated to the presence of C-O groups [12,15,22]. After chemical treatment, the presence of typical groups of the acetyl group in the infrared spectrum are indicative of reaction between the cellulose and the acetic anhydride. The decrease in intensity of the band associated with hydroxil groups can also be observed in the acetylated cellulose.

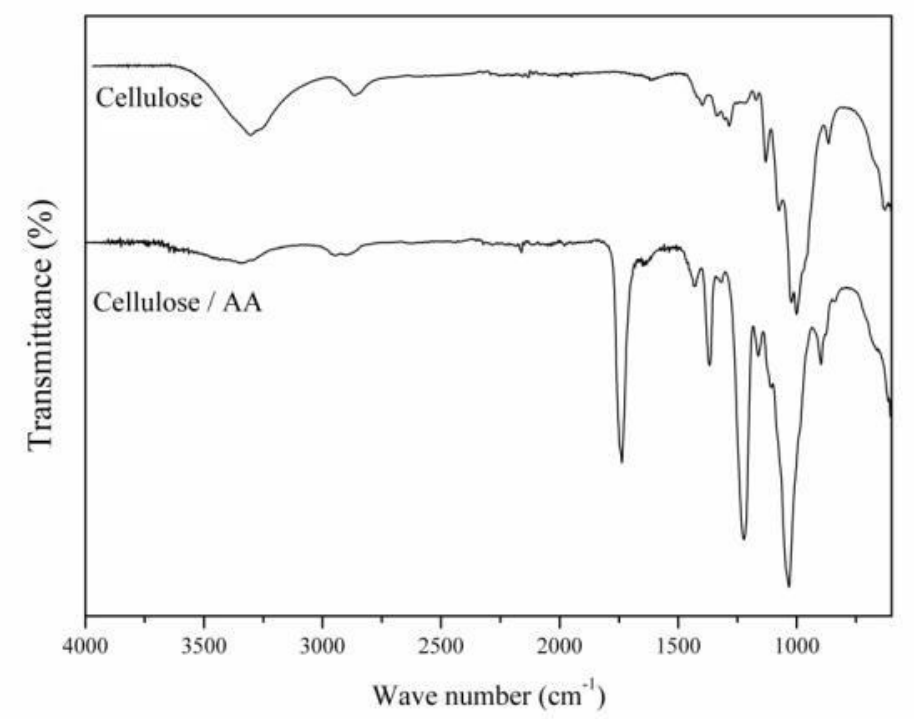

Figure 3: FTIR spectra of cellulose and acetylated cellulose (Cellulose/AA).

Thermogravimetric analyses of neat cellulose and acetylated cellulose are shown in Figure 4 . The first event, between 60 and $100^{\circ} \mathrm{C}$, is related to the presence of moisture in the cellulose [23-24], where it is observed that neat cellulose had a weight loss of $5 \%$ due to high hydrophilicity of neat cellulose. After the chemical treatment this phenomenon is no longer observed, because the treatment promotes the substitution of the hydroxyls by acetyl groups, thus increasing their hydrophobicity, and repelling water infiltration in the acetylated fibers. The second event is related to cellulose degradation. An increase in the thermal stability of acetylated cellulose is observed when compared to neat cellulose, observed by the displacement of the TG curve. This increase in thermal stability is due to acetyl groups are more thermally stable than hydroxyl groups.

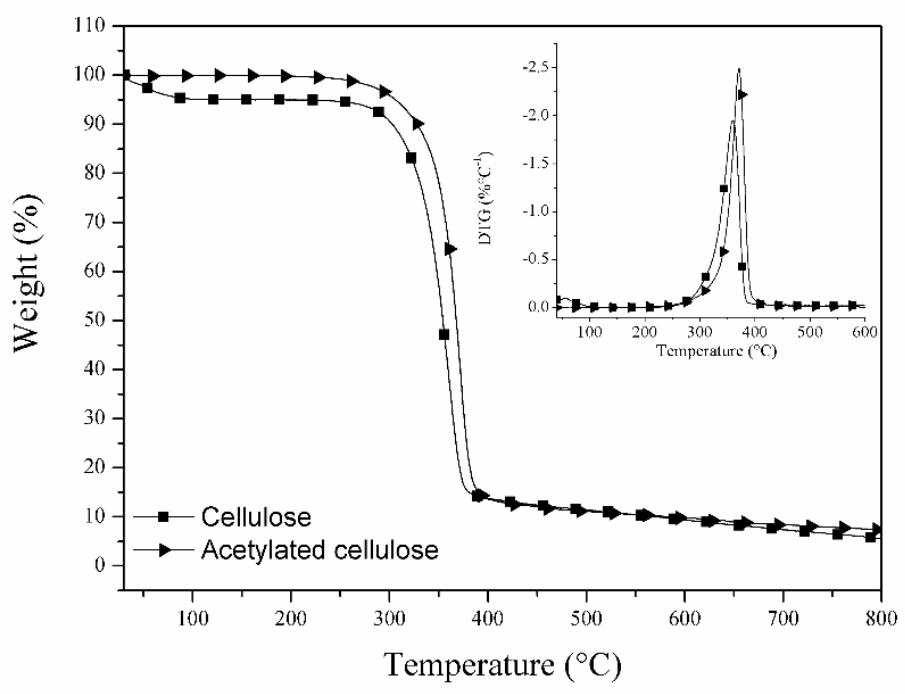

Figure 4: Thermogravimetric analyses of neat cellulose and acetylated cellulose.

The morphology of the cellulose fibers was analyzed before and after chemical treatment. Figure 5 
shows the micrograph obtained by SEM of neat and treated cellulose. In neat cellulose a texture with smooth surface is observed, with few irregularities. Since the acetylated cellulose has a rough surface with large erosion surface and crusts after the chemical treatment, showing some cracked regions, as well as detachment of layers and the formation of precipitates on the surface of the fiber, which may be due to the aggressiveness of the acidity of the chemical treatment.

Jonoobi et al. (2010) [15] show that a greater roughness of the acetylated cellulose fibers depends largely on the presence of catalysts (in this case, the NBS) to promote the infiltration of reagents (acetic anhydride and acetic acid) into the interior of the cellulose fibers, thus breaking part of its cellular structure on the surface.

Figure 5: SEM micrographs of (a) neat cellulose and (b) acetylated cellulose.
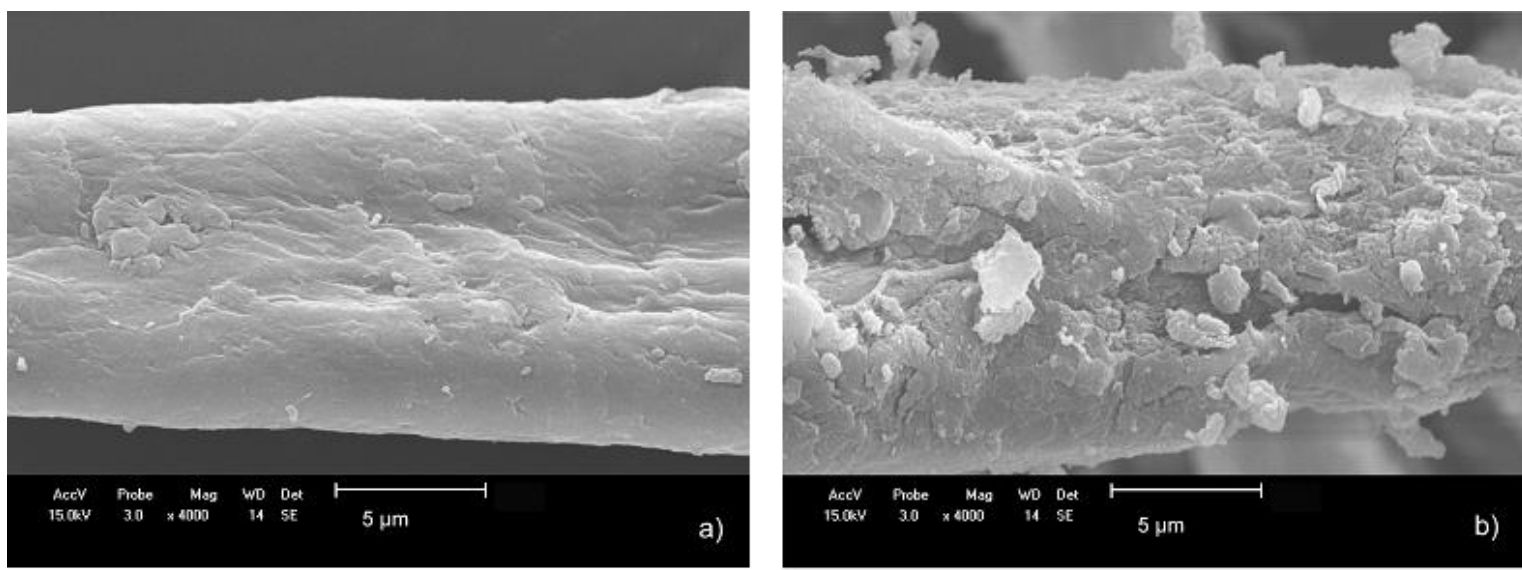

Figure 6 shows SEM micrographs of cellulose fibers before and after mechanical defibrillation. It is possible to observe a significant reduction in the size of the fibers when compared neat cellulose with MFC (Figures 6a and 6b). After mechanical desfibrilation, it can be observed the presence of some microfibers with approximate diameters of $5 \mu \mathrm{m}$ and in parallel to these, it also observed the presence of nanofibers with diameters from 200 to $50 \mathrm{~nm}$. It was not observed significant difference in fiber size between MFC and acetylated MFC (MFC / AA).
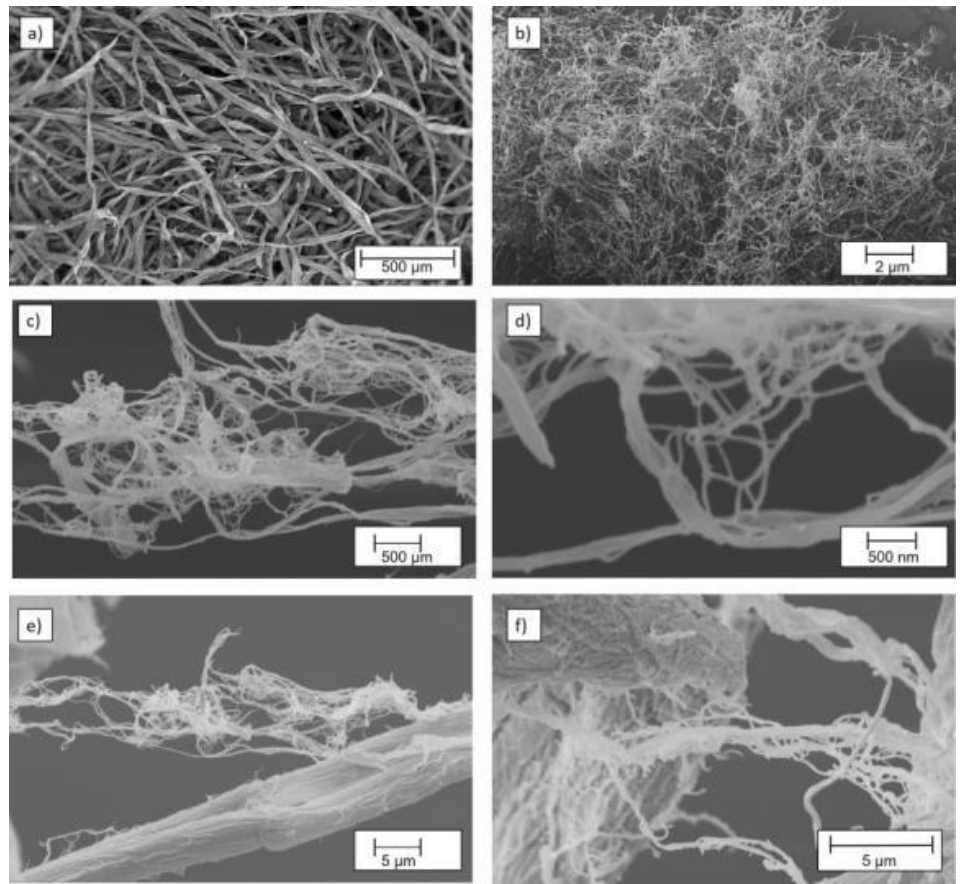

Figure 6: SEM micrographs of (a) cellulose fibers before mechanical desfibrilation (b) MFC after mechanical desfibrilation (c) and (d) MFC; (e) and (f) MFC / AA.

Figure 7 shows the comparative results from static sorption with the variation of the type of oil and us- 
ing sorbents with polyester envelope (type b). In this experiment it the effect of the fibrillation process was compared on both neat and treated cellulose fibers, comparing with no-milled cellulose fibers. It was also evaluated the water sorption capacity of the sorbents, based on the same methodology used for the oil sorption evaluation.

It was observed that the acetylated cellulose exhibited lower water sorption when compared to untreated cellulose samples. This lower sorption capacity is attributed to the chemical treatment, that increase the hydrophobicity of cellulose as previously described.

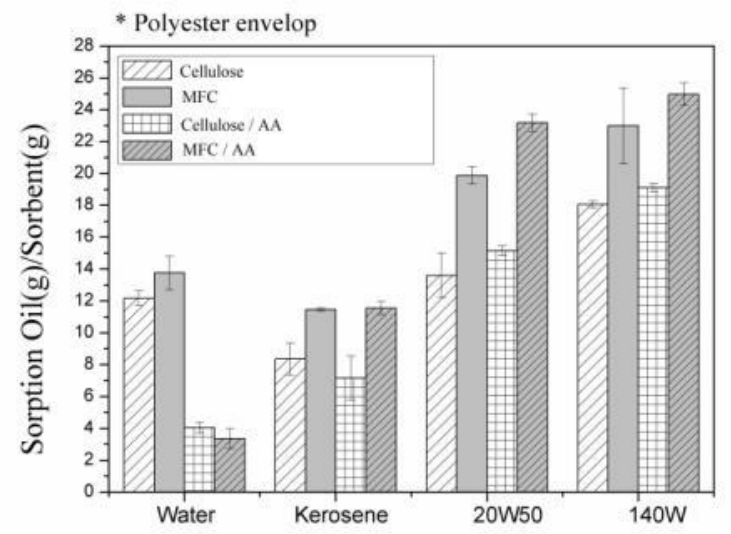

Figure 7: sorption capacity of the sorbent cellulose according to the type of oil or water.

When comparing the three types of oil, it is possible to observe a trend for increasing the sorption capacity of all samples with increased oil viscosity used in the assay. This growth it is associated to the desorption capacity and the flow of the oil when removed from the system. Considering that the flow time adopted was of 15 seconds for all samples, it may possibly have influenced the sorbent retention of the oil.

The increase in the contact area, promoted by mechanical defibrillation, results in an increase in static sorption capacity of the sorbent MFC and acetylated MFC. However, as seen in Figure 7, MFC has a high capacity for water sorption as well, and considering its application as a sorbent for marine environments, having a higher affinity to absorb water is not functional. But the acetylated MFC sorbent, besides presenting high sorption capacity, has a low degree of water sorption.

Figure 8 shows a sorption graph comparing the different envelope types used. It is observed that with a more open mesh tissue, smaller is the oil retaining of the sorbent. Higher sorption values are observed on the sorbent produced with PP envelope (type c). The oil sorption capacity is influenced by both adsorption and desorption (the flow time of the oil after removal from the oleophilic medium).

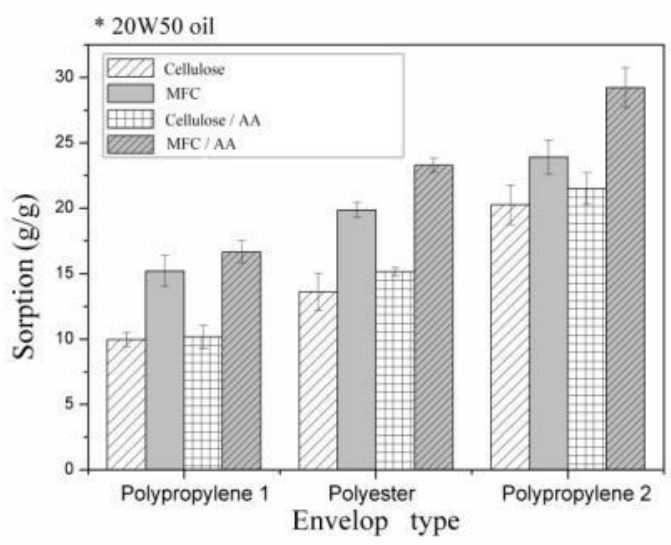

Figure 8: Oil sorption as a function of the type of envelope used owith the sorbent.

Figure 9 shows the test results of oil sorbents produced with acetylated MFC and of a commercial 
sorbent based on polypropylene fibers, all tested in the three different types of envelopes. When comparing the two sorbents, the system manufactured with acetylated MFC sorption showed superior results if compared to the commercial sorbent PP in all samples with different envelopes.

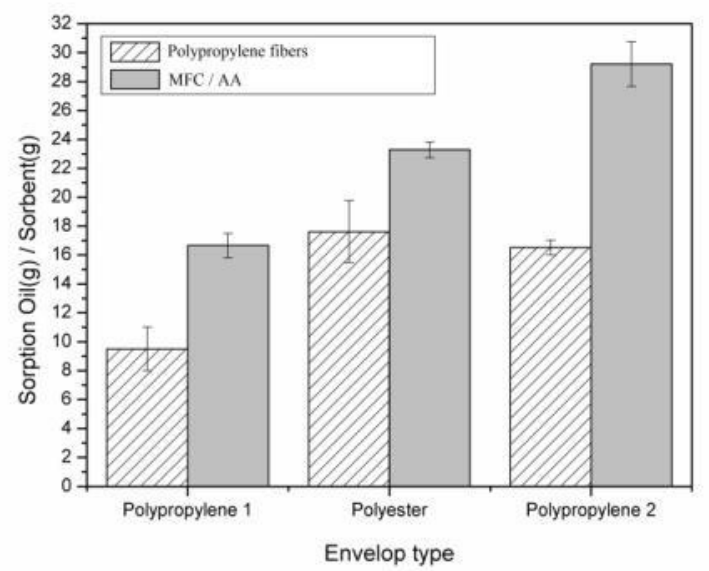

Figure 9: Oil sorption of two different types of sorbent.

\section{CONCLUSIONS}

This work studies cellulose modification by combining a mechanical and a chemical process in order to produce a high hydrophobic material with large contact area. Thus, considering it an interesting material for use as an oleophilic sorbent for recovery of spilled oils in marine environments. The acetylation process was confirmed by FTIR and TGA analysis. Morphological changes of cellulose were observed by SEM. The presence of micro and nanofiber after the mechanical process of fibrillation was observed on the surface of the cellulose after the mechanical desfibrilation. Regarding the sorption tests, low water sorption capacity of the acetylated MFC was observed. The sorption capacity of the acetylated MFC was superior to all evaluated sorbents systems, even when compared to a commercial sorbent produced by polypropylene fiber. Considering the type of envelope used, a higher oil retention by the sorbent coated with PP envelope (type C) was observed, due to the smaller mesh opening of this tissue..

\section{ACKNOWLEDGMENTS}

The authors gratefully acknowledge the Laboratório de Polímeros da Universidade de Caxias do Sul, the Conselho Nacional de Pesquisa e Desenvolvimento (CNPq) and Secretaria da Ciência, Inovação e Desenvolvimento do Rio Grande do Sul (SCT/RS) for the financial support.

\section{BIBLIOGRAPHY}

[1] LIM, T.T., HUANG, X, "Evaluation of kapok (Ceibapentandra (L.) Gaertn.) as a natural hollow hydrophobic-oleophilic fibrous sorbent for oil spill cleanup", Chemosphere, v. 66, pp. 955-963, 2007.

[2] LI, J., LOU, M., ZHAO, C.J., et al., "Oil removal from water with yellow horn shell residues treated by ionic liquid”, Bioresource Technol, v. 128, pp. 673-678, 2013.

[3] NGUYEN, S.T., FENG, J.S.K.N., WONG, J.P.W., et al., "Advanced thermal insulation and absorption properties of recycled cellulose aerogels", Colloids and Surfaces A: Physicochem and Eng. Aspects, v. 445, pp. 128-134, 2014.

[4] DUONG, H.T.T., BURFORD, R.P. "Effect of Foam Density, Oil Viscosity, and Temperature on Oil Sorption Behavior of Polyurethane”, J Appl Polym Sci, v. 99, pp. 360 -367, 2006.

[5] REYNOLDS, J.G., CORONADO P.R., HRUBESH, L.W. "Hidrophobic aerogels for oil-spill clean up synthesis and characterizarion”, J Non-Crystalline Solids, v. 292, pp. 127-137, 2001.

[6] BAYAT, A., AGHAMIRI, S.F., MOHEB, A., et al., "Oil Spill Cleanup from Sea Water By Sorbents Materials", Chem Eng Technol, v. 12, pp. 1525- 1528, 2005.

[7] ADEBAJO, M.O., FROST R.L., KLOPROGGE, J.T., et al., "Porous materials for oil spill cleanup: a review of synthesis and absorbing properties", J Porous Mater, v. 10, v.3, p.159-70, 2003. 
[8] PAYNE, K.C., JACKSON, C.D., AIZPURUNA, C.E., et al., "Oil Spills Abatement: Factors Affecting Oil Uptake by Cellulosic Fibers”, Environ Sci Technol. v. 46, n.14, pp. 7725-30, 2012

[9] HON, D.N.S. Wood and cellulosic chemistry. New York, Ed. Marcel Dekker, 2000.

[10] KABIR, M.M., WANG, H., LAU, K.T., et al., "Chemical treatments on plant-based natural fibre reinforced polymer composites: An overview”, Compos Part-B, v. 43, p. 2883-2892, 2012

[11] CHANG, C.Y., ZHANG L.N. "Cellulose-based hydrogels: Present status and application prospects", Carbohyd Polym, v. 84, v.1, pp. 40-53, 2011.

[12] CHUNG, S., SUIDAN M.T., VENOSA A.D. "Partially Acetylated Sugarcane Bagasse for Wicking Oil from Contaminated Wetlands", Chem Eng Technol, v. 34, pp. 1989-1996, 2011.

[13] SUN, X.F., SUN, R.C., SUN, J.X. "Acetylation of sugarcane bagasse using NBS as a catalyst under mild reaction conditions for the production of oil sorption-active materials", Bioresource Technology, v. 95(3), p. 343-350, 2004.

[14] NAGARAJAPPA, G.B., PANDEY, K.K., SHINDE, A.S., et al., "N-Bromosuccinimide (NBS) - an efficient catalyst for acetylation of wood", Holzforschung, v. 70, n.5, 2015.

[15] JONOOBI, M., HARUN, J., MATHEW, A.P., et al., "Preparation of cellulose nanofibers with hydrophobic surface characteristics", Cellulose, v. 17, pp. 299-307, 2010.

[16] DURÁN, N., MATTOSO, L.H.C., MORAIS, P.C. Nanotechnology: introduction, preparation and characterization of nanomaterials and application examples. São Paulo, Ed. Artliber, 2006.

[17] SAUNDERS, R.E., PAWLAK, J.J., LEE, J.M. "Properties of surface acetylated microfibrillated cellulose relative to intra- and inter-fibril bonding", Cellulose, v. 21, pp. 1541-1552, 2014.

[18] KALIA, S., BOUFI, S., CELLI, A., et al., "Nanofibrillated cellulose: surface modification and potential applications", Colloid Polym Sci, v. 292, pp. 5-31, 2014.

[19] PENG, Y., GARDNER D.J., HAN, Y. "Drying cellulose nanofibrils: in search of a suitable method", Cellulose, v. 19, pp. 91-102, 2012.

[20] DINIZ, J.M.B.F., GIL, M.H., CASTRO, J.A.A.M. "Hornification-its origin and interpretation in wood pulps” Wood Sci Technol, pp. 37, v. 489-494, 2004.

[21] ZIMMERMANN, M.V.G., BORSOI, C., LAVORATTI, A., et al., "Drying techniques applied to cellulose nanofibers", J Renfor Plast Compos, v. 35 n.8, pp. 628-643, 2016.

[22] SUN, X., SUN, R., SUN, J. "Acetylation of rice straw with or without catalysts and its characterization as a natural sorbent in oil spill cleanup", Agric Food Chem, v. 50, pp. 6428-6433, 2002.

[23] MADERA-SANTANA, T.J., SOTO, VALDEZ, H., RICHARDSON, M.O.W. "Influence of surface treatments on the physicochemical properties of short sisal fibers: Ethylene vinyl acetate composites", Polym Eng Sci, v. 53, pp. 59-68, 2013.

[24] LU, N., OZA, S. "Thermal stability and thermo-mechanical properties of hemp-high density polyethylene composites: Effect of two different chemical modifications", Compos Part-B Eng, v. 44, pp. 484-490, 2013.

\section{ORCID}

Matheus Zimmermann

Ademir J Zattera

Ruth Marlene Campomanes Santana https://orcid.org/0000-0001-5851-7270

https://orcid.org/0000-0002-2198-4323

https://orcid.org/0000-0001-6843-9915 